\title{
DEFECT DETECTION OF HISTORIC STRUCTURES IN DARK PLACES BASED ON THE POINT CLOUD ANALYSIS BY MODIFIED OptD METHOD
}

\author{
W. Błaszczak-Bąk ${ }^{1,}{ }^{*}$, C. Suchocki ${ }^{2}$, J. Janicka ${ }^{1}$, A. Dumalski ${ }^{1}$, R. Duchnowski ${ }^{1}$ \\ ${ }^{1}$ Institute of Geodesy, Faculty of Geodesy, Geospatial and Civil Engineering, University of Warmia and Mazury in Olsztyn, \\ Oczapowskiego St. 1, Olsztyn, Poland \\ ${ }^{2}$ Koszalin University of Technology, Faculty of Civil Engineering Environmental and Geodetic Sciences, Śniadeckich 2, 75-453 \\ Koszalin, Poland
}

Commission VI, WG VI/4

KEY WORDS: point cloud, Terrestrial Laser Scanning, reduction, segmentation, OptD method, defects

\begin{abstract}
:
Data provided by Light Detection And Ranging (LiDAR) can be very useful, and their applications are very diverse. Information about the reflection, its intensity values of individual points give the possibility of a realistic visualization of the entire scanned object. This use of LiDAR is very important in improving safety and avoiding disasters. The use of LiDAR technology allows to 'look' and extract information about the structure of the object without the need for external lighting or daylight. In the paper the results of Terrestrial Laser Scanning (TLS) measurements conducted by means of the Leica C-10 scanner will be presented. The measurement will be performed in rooms without daylight: in the basement of the ruins of the medieval tower located in Dobre Miasto and in the basement of a century-old building located at the University of Warmia and Mazury in Olsztyn. Next, the obtained dataset of $\mathrm{x}, \mathrm{y}, \mathrm{z}$ and intensity will be processed using the Optimum Dataset (OptD) method. The application of the OptD allows to keep more points of interest area where surface is imperfect (e.g. cracks and cavities) and reduce more points of the low interest homogeneous surface (redundant information). The OptD algorithm was additionally modified by detecting and segmentation defects on a scale from 0 to 3 such as (0) harmless, (1) to the inventory, (2) requiring repair, (3) dangerous. The obtained survey results proved the high effectiveness of the modified OptD method in detection and segmentation wall defects.
\end{abstract}

\section{INTRODUCTION}

The growing interest of investors in the revitalization of buildings under conservation protection has resulted in the need to quickly and accurately perform inventory, measurements and research necessary in the process of designing and obtaining decisions of conservation offices. 3D laser scanning is a documentation method that is great for studying monuments. The extensive use of 3D laser scanning in the preservation of monuments, architectural inventory or archaeological research allows to obtain very precise measurements and information about the object, and significantly accelerates the performance of these activities in the field (Altuntas, Yildiz, \& Scaioni, 2016), (Jo \& Hong, 2019), (Yastikli, 2007), (Pavlidis, Koutsoudis, Arnaoutoglou, Tsioukas, \& Chamzas, 2007).

The acquired point cloud consists of millions of threedimensional measurement points and is an exact digital copy of the existing state of affairs. Detection of material degradation in historic buildings with traditional methods, for example manual mapping or simple eye examination by an expert (Almagro Gorbea, 2002), are considered time-consuming and laborious procedures, so TLS technology and image processing methodologies are being developed, allowing for the detection of pathologies, their evolution (Fregonese et al., 2013), identification of deformations and changes in material (Del Pozo et al., 2016), (Corso, Roca, \& Buill, 2017). Laser scanning technology allows to build a complete 3D model based on the point cloud (Alby \& Grussenmeyer, 2012), (Previtali et al., 2014). Thanks to the built-in digital camera, along with scanning, complete photographic documentation of the object is collected, which can be placed on the point cloud as a texture. This combination of two documentary methods, i.e. laser scanning and photos, allows to obtain the necessary data about the object, and above all information about defects, gaps, cracks. Such a study is clear to architectural designers who work on the revitalization and adaptation of historic architecture. In addition, based on the point cloud obtained, you can make a precise dimensioned model of the building in 3D, which can be freely changed while maintaining the actual proportions. Many old, monumental objects are not equipped with electric power. Often, such facilities contain dark, unlit places, such as basements, tunnels, underground, without access to daylight. The great advantage of laser scanning is the total independence of measurements from lighting conditions - as active devices, not passive ones, laser scanners can work in complete darkness.

TLS provide a point cloud with very high resolution. Very often such a high resolution is not needed in the whole area under investigation. Thus, automatic down-sampling of point cloud and its segmentation is needed. It should be noted that, the reduction and segmentation of point clouds is currently special interest research topic (Du \& Zhuo, 2009), (Lin, Benziger, \& Habib, 2016), (Maglo, Lavoue, Dupont, \& Hudelot, 2015),

\footnotetext{
* Corresponding author
} 
(Grilli, Menna, \& Remondino, 2017), (Nguyen \& Le, 2013). So far, authors have conducted a thorough and successful research program dedicated to the reduce of dataset from TLS measurements of buildings and structures in the context of them technical diagnostics (Suchocki \& Błaszczak-Bąk, 2019), (Suchocki, Błaszczak-Bąk, Damięcka-Suchocka, Jagoda, \& Masiero, 2019). In these studies, the OptD method was used. The applied OptD method reduced redundant information on homogeneous areas without cracks and cavities of the surface and retains more points on wall defects simultaneously. In current studies, the OptD method was modified in such a way that, in apart from down-sampling of the point cloud, the dataset was segmented. The segmentation of the reduced point cloud is divided on four groups. Each group is classified by the size of the changes on the surface of the wall. Analysis of the point clouds can be performed in the $3 \mathrm{D}-\mathrm{OXYZ}$ coordinate system, which allows to detect recesses (cavities and cracks) on the building wall. In addition, one can carry out analyses in the OXYI coordinate system (where I - the TLS intensity value), which allows to detect local surface changes of the wall, e.g., moisture, discoloration, bio-deterioration (moss and lichen) etc. Such changes on the buildings and structures are very often associated with poor technical conditions of the surface. Note that, the TLS intensity value depends mainly on the physicochemical properties of scanned areas such as colour, roughness, and saturation (Voegtle, Schwab, \& Landes, 2008), (Oren \& Nayar, 1994), (C Suchocki \& Katzer, 2018), (Suchocki, Jagoda, Obuchovski, Šlikas, \& Sužiedelytè-Visockienè, 2018). The choice of way dataset analysis (OXYZ or OXYI coordinate system) depends on the user. The user can choose two ways at the same time.

The main aim of this study is demonstrate the potential of the modified OptD method to down-sampling of point cloud and its segmentation simultaneously in the context of fully automatic defect detection on the building wall.

\section{MATERIALS AND METHODS}

The OptD method has already been presented in the papers (Błaszczak-Bąk, 2016), (Błaszczak-Bąk, Sobieraj-Żłobińska, \& Kowalik, 2017). The OptD method is used to reduce the number of observations in mass data acquisition technologies. Its use allows to down-sample the big dataset even in the range from $0.05-99.95 \%$. The degree of reduction of the dataset depends on the user, on the purpose of the study, the number of input datasets. The algorithm of the method works in such a way that in the plane of the object (in this case the wall) measuring strips $(\mathrm{L})$ are created in which the analysis of points located in a given strip is performed using the cartographic generalization method (here Douglas-Peucker method) (Douglas \& Peucker, 1973).

The spatial nature of the output file is ensured by the fact that the generalization is performed in OXZ plane, therefore the height changes are preserved. It is also possible to analyse the intensity of the reflection of the laser signal, which allows you to save changes resulting from e.g. moisture.

In this article, we propose to modify the OptD method of reducing the point cloud with automatic dataset segmentation in the context of detecting defects in a building wall. The modification takes place on three levels:

1. Introduction of additional internal criteria in the Douglas-Peucker algorithm.

2. Introduction of codes in the output file - modification of the output file.txt.

3. Introduction of colors for the relevant codes modification on the image.
The introduced modifications are shown in the Figure 1.

The first modification consists in entering a new condition while checking the distance from the baseline in the DouglasPeucker algorithm. The calculated distance from the baseline is different for each approximation. This distance is compared to the established tolerance range and in this way we can determine whether the point remains at the set or is removed, and also with what size change we are dealing with. In addition to the tolerance range (t), you can enter the values of the intervals to determine the amount of change. By introducing the division into changes: harmless $(h)$, to the inventory $(i)$, required repair $(r)$, dangerous $(d)$, we can enter for them min and max values: hmin and hmax, imin and imax, rmin and rmax, dmin and dmax. The modification of generalization algorithm is present in Figure 2.

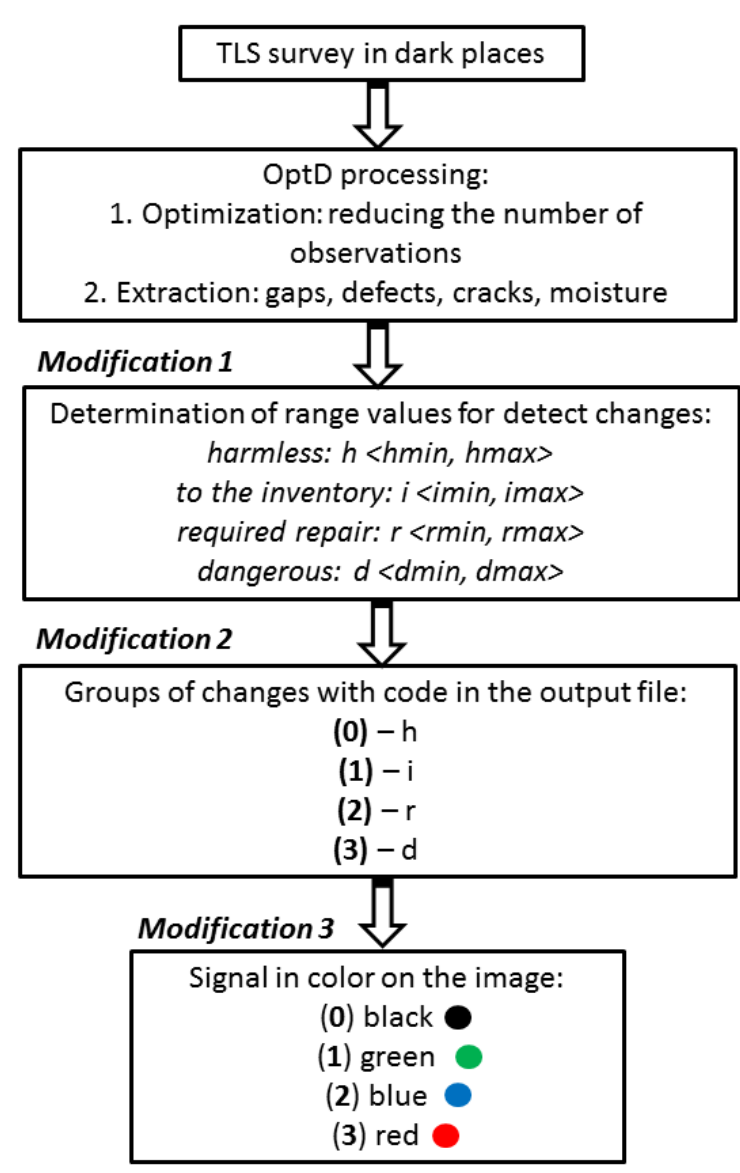

Figure 1. Introduced modification

Thanks to these values, during the operation of the OptD method, a second modification is possible, consisting in the fact that for points representing changes (cracks, gaps) added in the 'outputfile.txt' the additional column with codes: $h$ - code 0 , $i$ - code $1, r$ - code $2, d$ - code 3 .

The third modification, however, consists in illustrating changes in the image by giving colors to the appropriate codes. At presented paper, the following colors were accepted: 0 - black, 1 - green, 2 - blue, 3 - red. The colors allow you to clearly indicate on the image changes and assess which of these changes are dangerous. 


\section{DATA PROCESSING AND RESULTS}

Two test objects were selected. Both are monuments located in the warminsko-mazurskie voivodeship in Poland. The first one is in the city of Olsztyn. The building houses the headquarters of the Institute of Geodesy, University of Warmia and Mazury. The second object is the tower's ruin located in city Dobre Miasto with preserved fragment of the medieval walls. The object 1 and object 2 are presented in Figure 3.

(a) $\mathrm{Z}$

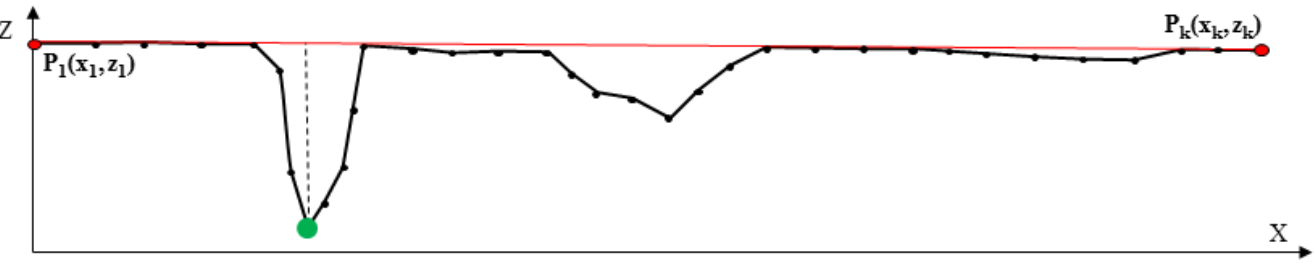

(b)

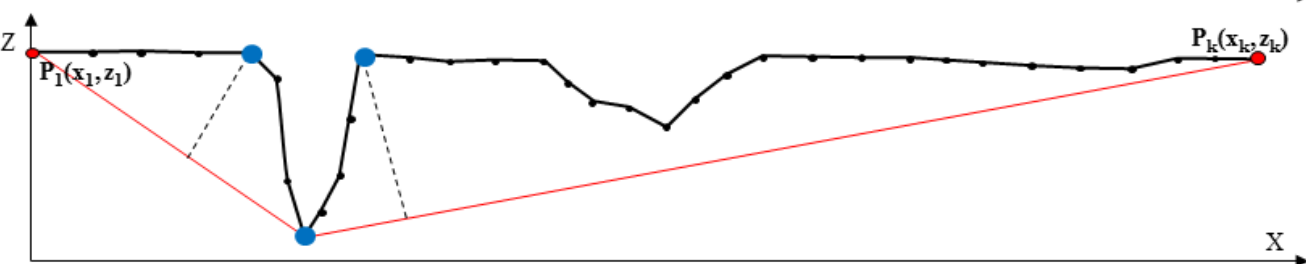

(c)

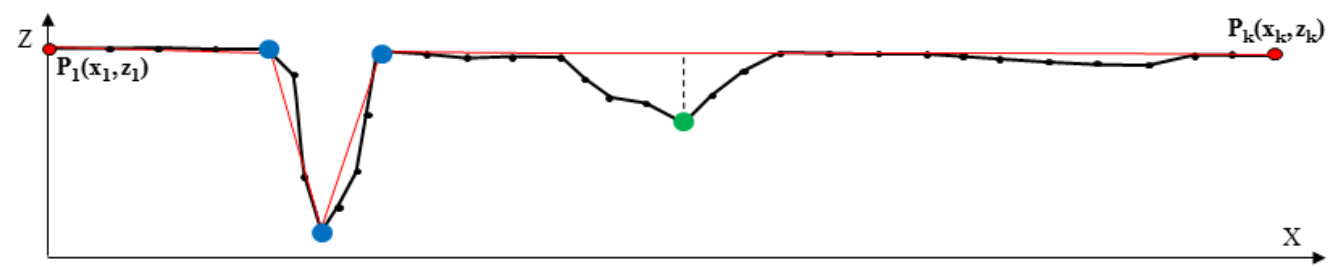

(d)

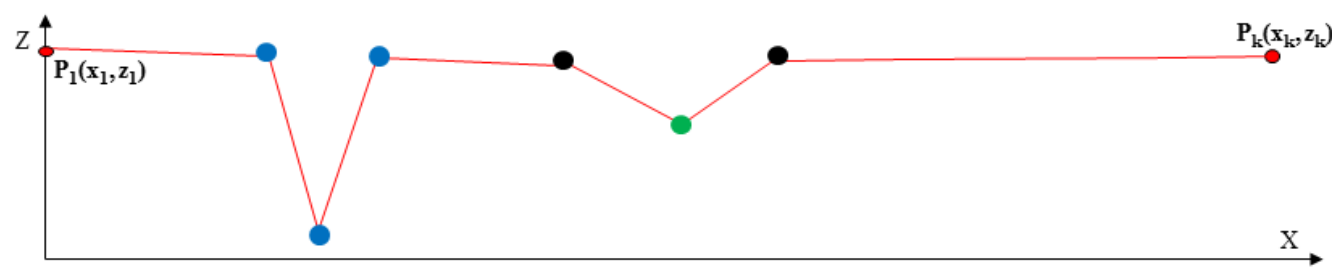

— line before Douglas-Peucker algorithm

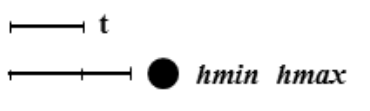

-.-.-- max distance

- points in original strip

- points in strip after generalization

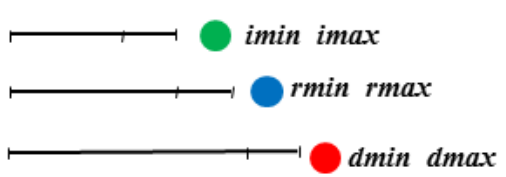

Figure 2. Introduced modification for Douglas-Peucker algorithm
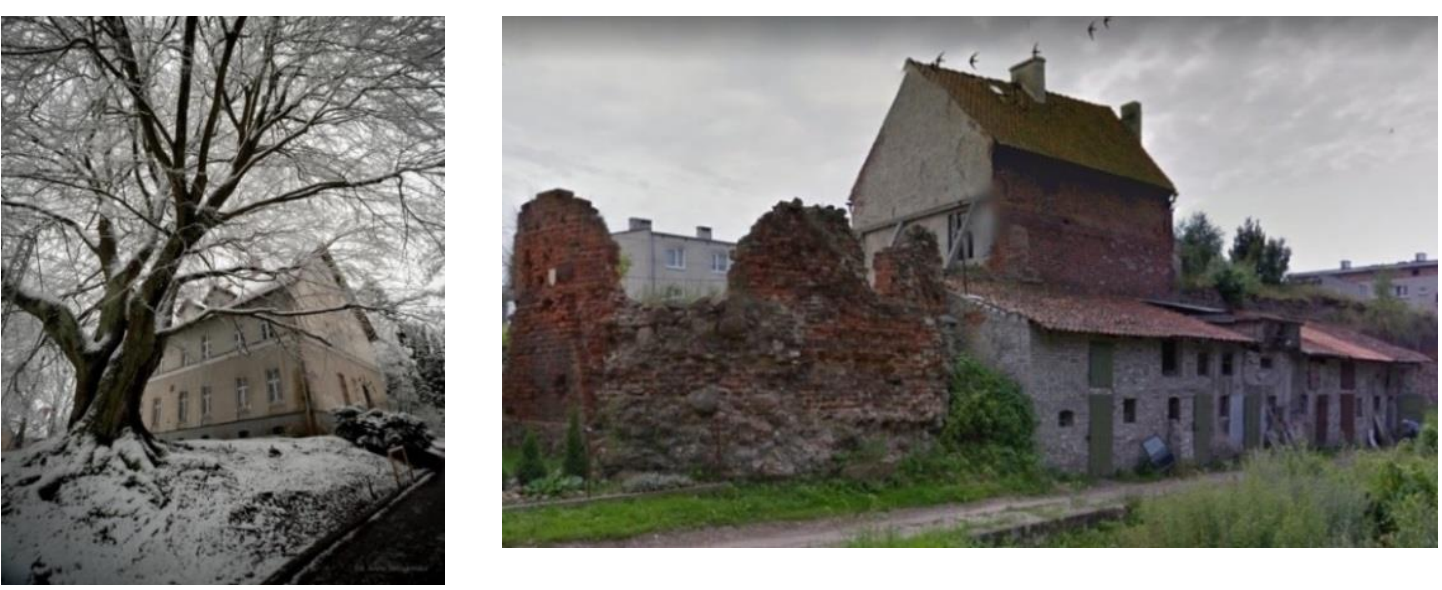

Figure 3. Object 1 an object 2 (source: photographed Anna Skrzypińska) 


\begin{tabular}{|c|c|c|c|c|c|c|c|}
\hline \multirow[b]{3}{*}{ fragments of data } & \multicolumn{5}{|c|}{ depend on user } & \multicolumn{2}{|c|}{$\begin{array}{c}\text { not depend on user } \\
\text { (change during iteration) }\end{array}$} \\
\hline & \multirow[b]{2}{*}{ p\% } & \multicolumn{4}{|c|}{ additional internal criteria for modified OptD } & \multirow[b]{2}{*}{$\mathbf{L}(\mathbf{m})$} & \multirow[b]{2}{*}{$\mathbf{t}(\mathbf{m})$} \\
\hline & & $\begin{array}{l}\text { hmin (m) } \\
\text { hmax (m) }\end{array}$ & $\begin{array}{l}\operatorname{imin}(\mathbf{m}) \\
\operatorname{imax}(\mathbf{m})\end{array}$ & $\begin{array}{l}\operatorname{rmin}(\mathbf{m}) \\
\operatorname{rmax}(\mathbf{m})\end{array}$ & $\begin{array}{l}\operatorname{dmin}(m) \\
\operatorname{dmax}(m)\end{array}$ & & \\
\hline Object1 fragment1 & 1 & $\begin{array}{l}0.006 \\
0.007\end{array}$ & $\begin{array}{l}0.008 \\
0.009\end{array}$ & $\begin{array}{l}0.010 \\
0.015\end{array}$ & $\begin{array}{l}0.016 \\
1.000\end{array}$ & 0.001 & 0.006 \\
\hline Object 1 fragment 2 & 1 & $\begin{array}{l}0.006 \\
0.007\end{array}$ & $\begin{array}{l}0.008 \\
0.009\end{array}$ & $\begin{array}{l}0.010 \\
0.015\end{array}$ & $\begin{array}{l}0.016 \\
1.000\end{array}$ & 0.001 & 0.006 \\
\hline Object 2 fragment & 1 & $\begin{array}{l}0.008 \\
0.010\end{array}$ & $\begin{array}{l}0.011 \\
0.015\end{array}$ & $\begin{array}{l}0.016 \\
0.020\end{array}$ & $\begin{array}{l}0.021 \\
1.000\end{array}$ & 0.002 & 0.008 \\
\hline
\end{tabular}

Table 1. Optimization criteria

These buildings are covered by a permanent inventory and are under the protection of a monument conservator. In the case of the building of the Institute of Geodesy, protection consists in the permanent performance of renovation works. Whereas in the case of the tower's ruin it is about keeping the fragments that have been in good condition. In the underground of these buildings there are basements with no access to daylight. In these basements the measurement was made with Leica C-10 scanner. From each measurement, for each research object, fragments of the set of observations were selected, which were processed by the modified OptD method. Fragments for object1 are walls, while fragment of object 2 is the basement ceiling.

In Table 1 the optimization criteria adopted during the OptD processing are presented. Values of $\mathrm{L}$ and $\mathrm{t}$ are given for the last iteration. To correctly set the criteria for segmentation, the OptD method in the basic version is first performed. In this way, the tolerance value is calculated and then the user can introduce the criteria for segmentation.

The second modification consisting in adding a code column looks like in the table of data presented in Table 2.

\begin{tabular}{|c|c|c|c|c|}
\hline $\boldsymbol{X}(\mathbf{m})$ & $\boldsymbol{V}(\mathbf{m})$ & $\boldsymbol{Z}(\mathbf{m})$ & intensity & $\begin{array}{c}\text { Code } \\
(\mathbf{0 , 1 , 2 , 3 )}\end{array}$ \\
\hline 0.5837 & 0.5426 & 0.1364 & -515.0000 & 1 \\
\hline 0.5709 & 0.5454 & 0.1396 & -629.0000 & 1 \\
\hline 0.5779 & 0.5479 & 0.1388 & -822.0000 & 1 \\
\hline 0.5818 & 0.5508 & 0.1358 & -728.0000 & 1 \\
\hline 0.5340 & 0.5524 & 0.1355 & -605.0000 & 1 \\
\hline 0.5194 & 0.5524 & 0.1385 & -568.0000 & 1 \\
\hline 0.6092 & 0.5526 & 0.1366 & -965.0000 & 1 \\
\hline 0.5123 & 0.5528 & 0.1335 & -519.0000 & 1 \\
\hline 0.5013 & 0.5538 & 0.1367 & -924.0000 & 1 \\
\hline 0.6489 & 0.5540 & 0.1383 & -707.0000 & 1 \\
\hline
\end{tabular}

Table 2. Fragment of outputfile.txt with code column

The third modification is visible on the images. Selected fragment and their analysis with modified OptD method of basements for object1 are presented in Figure 4 and Figure 5. Figure 4 presents that the proposed method shows the locations of moisture changes. Already at the preliminary stage of the analysis of the tested surfaces, it allows taking appropriate corrective actions in the field of water insulation. By performing subsequent scans within a certain period of time, it will be possible to determine whether the moisture of the walls will subside or will remain at a similar level or will deepen.

Figure 5 shows how the modified OptD method detects cracks in the wall. It very precisely indicates their location, although it is difficult to determine the cracking width.

Performing scanning from two positions at different angles could provide just such information. In this case, however, because these are preliminary analyzes, it is not about very precise information about damage, but about their initial location and quick taking of appropriate corrective actions. Selected fragment and their analysis with modified OptD method of basement for object 2 is presented in Figure 6.

Figure 6 presents exactly the places of cavities in the basement ceiling. As it can be seen, such defects, especially in places important for the construction of buildings, may lead to a violation of its stability and even to a construction disaster. So it is very important to fast make a diagnosis of the building and start to carry out corrective actions.

\section{DISCUSSION AND CONCLUSIONS}

In this paper the potential of the modified OptD method to down-sampling of point cloud and its segmentation was demonstrated.

Combining the possibilities of the OptD method with simultaneous classification gives the opportunity to study the structure of objects already at the stage of initial data processing. This is particularly important during measurements using TLS technology, because on the one hand a very large dataset of observations is obtained, and on the other hand for defect studies the only areas where there are changes are needed. Modification of the OptD method consisting in the introduction of segmentation for the points during in the course of reduction makes that an architect, a monument conservator, a construction worker can immediately notice a place on the site that needs to be controlled. The modification is visible in three levels: in the Douglas-Peucker algorithm, in the output file and in the form of colors in the image. In this article the authors introduced codes for four point groups: harmless, to the inventory, required repair, dangerous. Table 3 shows how many points in each of the examined objects have been classified according to fixed codes. 

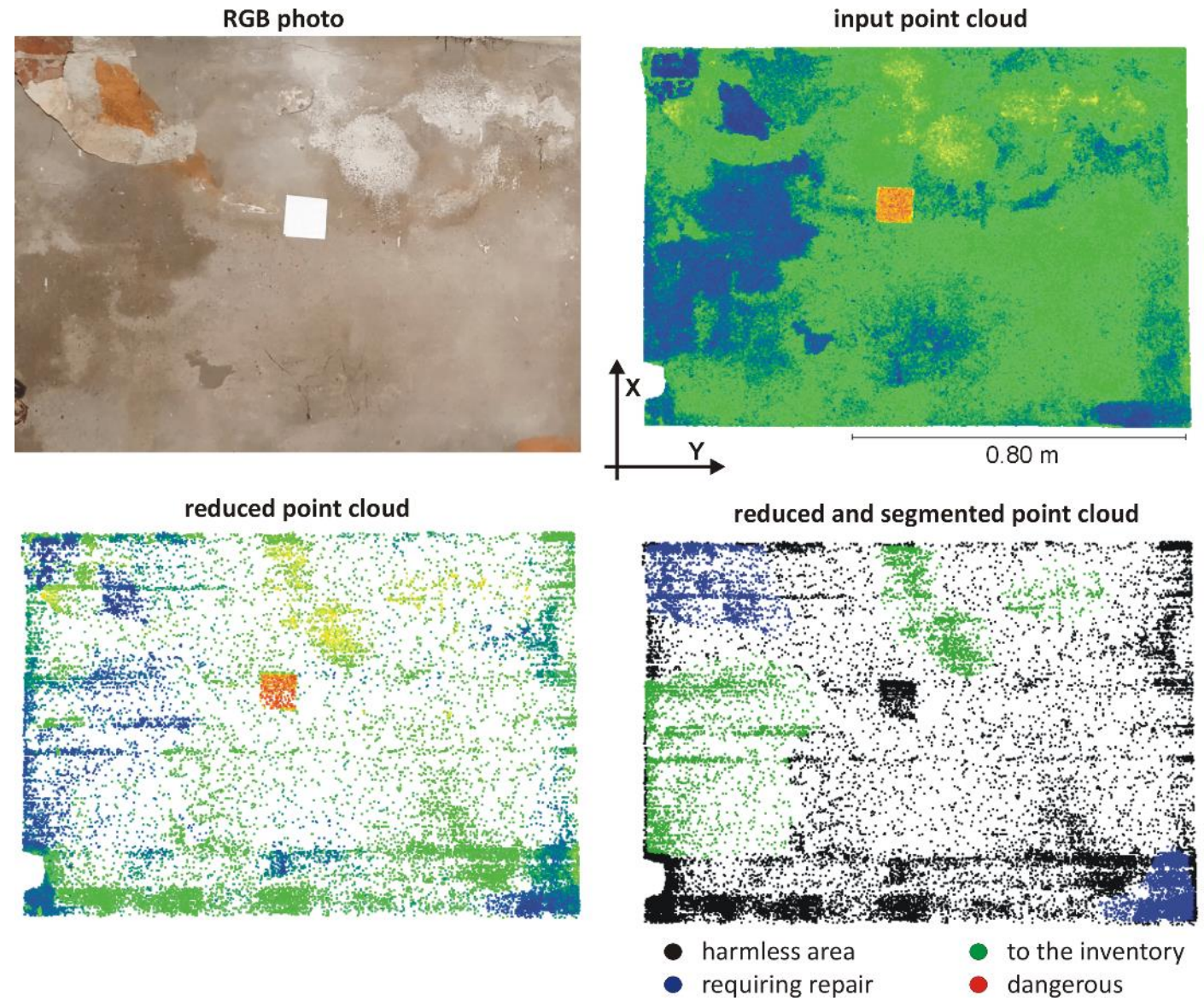

Figure 4. Detection of basement wall defects based on OptD segmentation in OXYI coordinate system - object1 fragment1
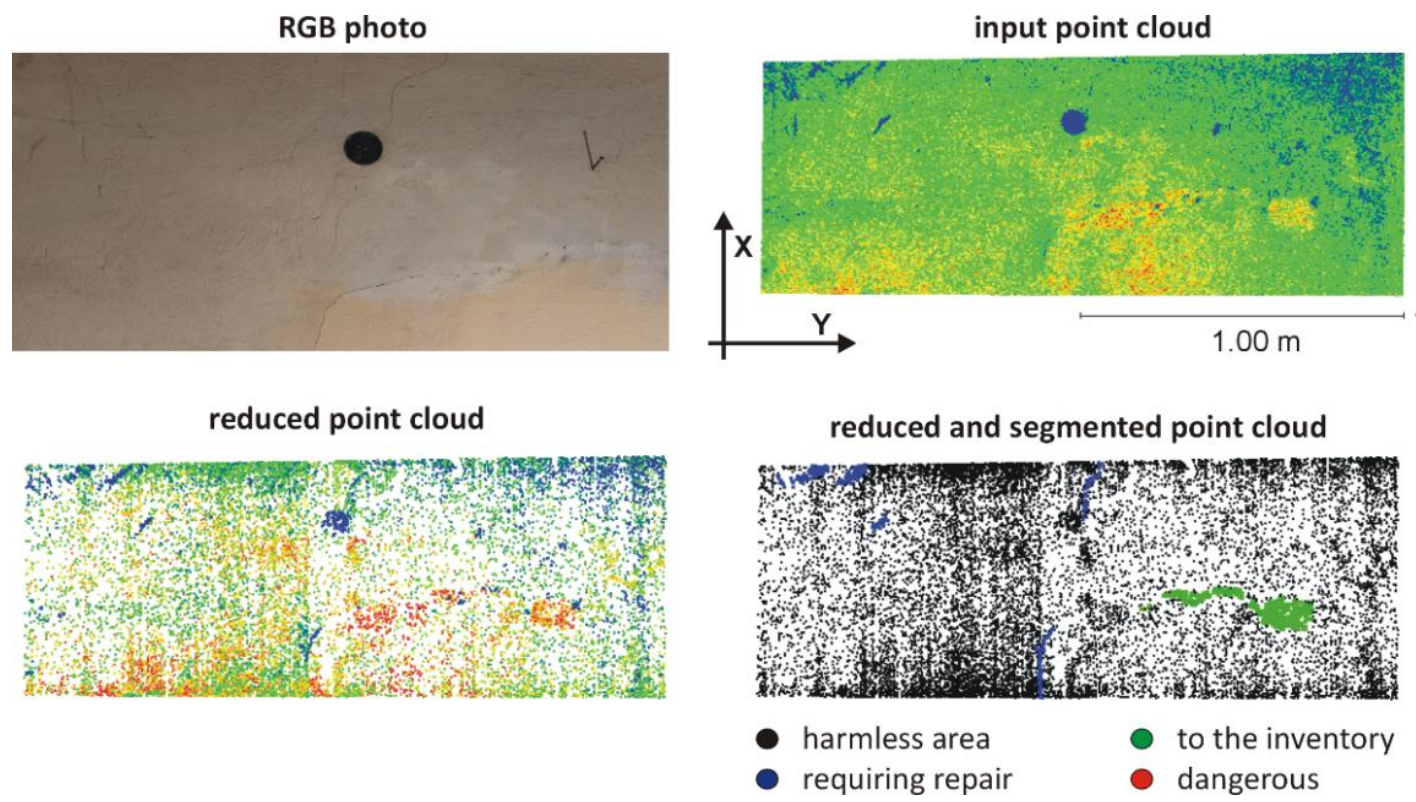

Figure 5. Detection of basement wall defects based on OptD segmentation in OXYI coordinate system - object1 fragment 2 

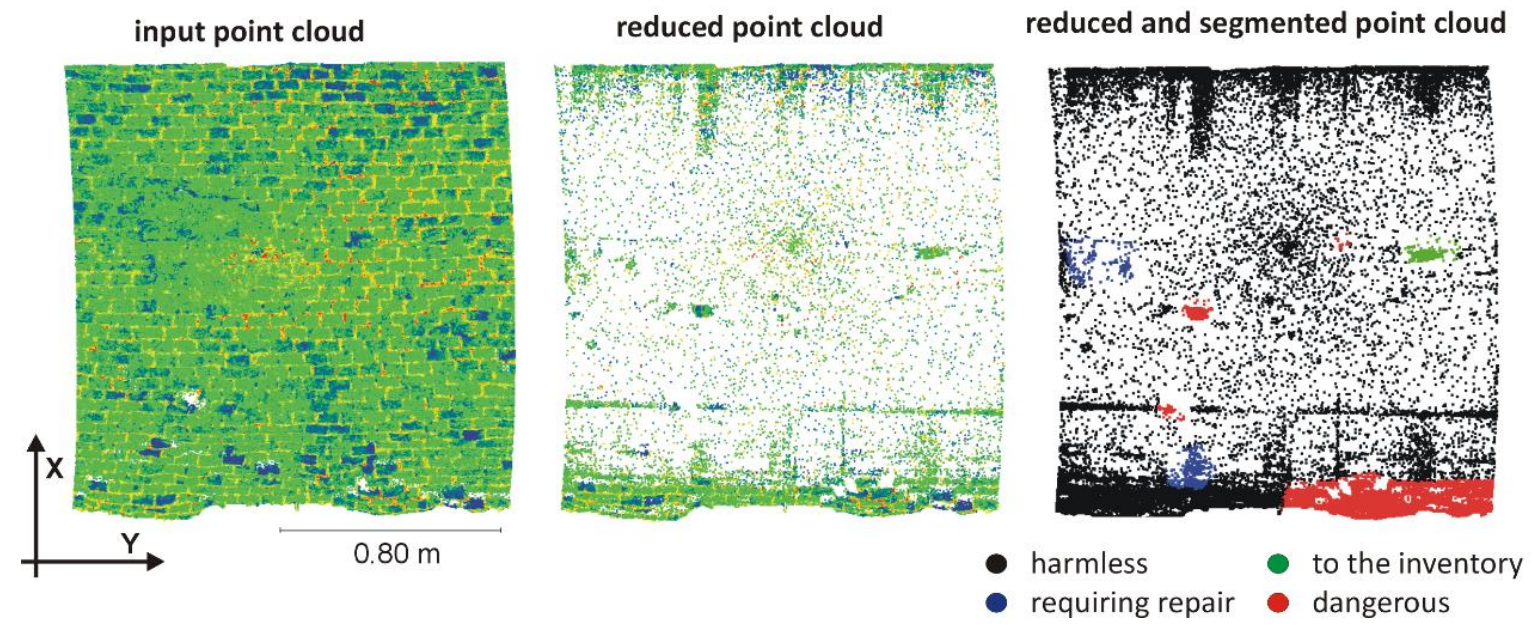

Figure 6. Detection of basement brick wall defects based on OptD segmentation in OXYZ coordinate system - object2

\begin{tabular}{|c|c|c|c|c|}
\hline \multirow{2}{*}{ objects } & \multicolumn{4}{|c|}{ number of points } \\
\cline { 2 - 5 } & code 0 & code 1 & code 2 & code 3 \\
\hline $\begin{array}{c}\text { Object1 } \\
\text { fragment1 }\end{array}$ & 18499 & 4898 & 7252 & - \\
\hline $\begin{array}{c}\text { Object1 } \\
\text { fragment2 }\end{array}$ & 17834 & 476 & 761 & - \\
\hline $\begin{array}{c}\text { Object2 } \\
\text { fragment }\end{array}$ & 26106 & 321 & 664 & 9811 \\
\hline
\end{tabular}

Table 3. The characteristic of the dataset after OptD for objects

The examined objects were measured in complete darkness. The independence of TLS measurements from lighting makes it possible to successfully carry out inventory measurements of endangered objects. It is not always possible to put out good photos in such dark places, where the changes in wall structures will be visible. Therefore, the modified OptD method allows to capture during the pre-processing the most important defects and to compute surface areas. The Table 4 presents areas calculated for individual groups of points.

\begin{tabular}{|c|c|c|c|c|c|}
\hline \multirow{2}{*}{ objects } & \multicolumn{5}{|c|}{ area $\left[\mathrm{m}^{2}\right]$} \\
\cline { 2 - 6 } & $\begin{array}{c}\text { whole } \\
\text { object }\end{array}$ & code 0 & code 1 & code 2 & code 3 \\
\hline $\begin{array}{c}\text { Object1 } \\
\text { fragment1 }\end{array}$ & 4.945 & 4.483 & 0.391 & 0.071 & - \\
\hline $\begin{array}{c}\text { Object1 } \\
\text { fragment2 }\end{array}$ & 0.759 & 0.711 & 0.030 & 0.018 & - \\
\hline $\begin{array}{c}\text { Object2 } \\
\text { fragment }\end{array}$ & 4.833 & 4.299 & 0.137 & 0.035 & 0.362 \\
\hline
\end{tabular}

Table 4. Area of defects

Such information about the magnitude of changes as well as their humidity can be the basis for further important works related to conservation, reconstruction of old buildings. It is of course extremely important or even essential for estimating the presumed repair or recovery costs.

The largest changes in the wall structure were detected for object 2 . The dmax parameter was entered as a value of up to
$1.000 \mathrm{~m}$. The largest change was $0.321 \mathrm{~m}$ for a large area of changes distinguished as dangerous. The change has been patented in the Figure 7.
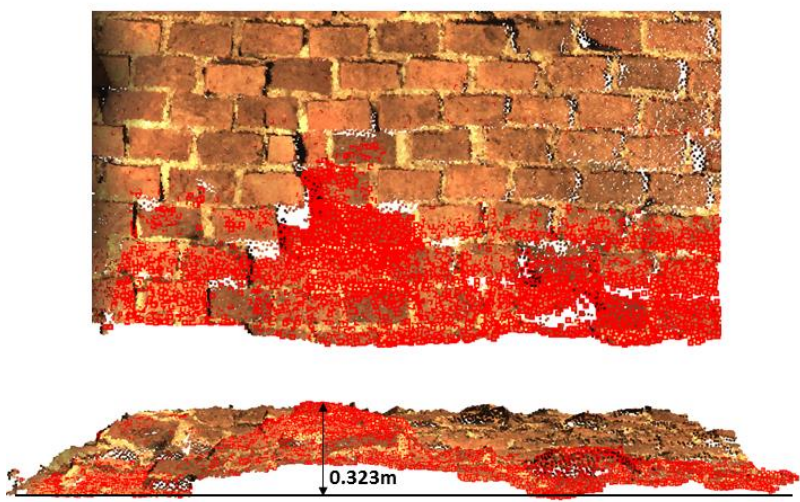

Figure 7. Maximum brick wall defects for object2

By summarizing the results of the tests the following general conclusions can be formulated:

1. The modified OptD method gives the possibility of reduction with simultaneous segmentation of points left in the set after reduction.

2. The modified OptD method is dedicated to the preprocessing of acquired observations from TLS to investigate changes in the wall structure.

3. The result of operation of the modified OptD method can be seen in the output file in the form of codes from 0 to 3 . The number of codes can be chosen arbitrarily by the user.

4. The codes correspond to the colors that are visible in the image. They give the opportunity to quickly identify significant changes in the structure of the walls.

5. The modified OptD method can be used during the inventory of construction works.

Author Contributions: conceptualization, W.B-B.; obtaining data A.D. and R.D.; analysis, and interpretation of data C.S.; Methodology, W.B-B and C.S.; Software, W.B.B.; Visualization, C.S.; writing - review and editing, J.J. 


\section{REFERENCES}

Alby, E., \& Grussenmeyer, P. (2012). From point cloud to 3D model, modelling methods based on architectural knowledge applied to fortress of châtel-sur-moselle (France). ISPRS - International Archives of the Photogrammetry, Remote Sensing and Spatial Information Sciences, XXXIX-B5, 75-80. https://doi.org/10.5194/isprsarchives-Xxxix-b5-752012

Almagro Gorbea, A. (2002). Simple Methods of Photogrammetry: Easy and Fast. XVIII International Symposium of CIPA, Potsdam September 18-21 2001.

Altuntas, C., Yildiz, F., \& Scaioni, M. (2016). Laser Scanning and Data Integration for Three-Dimensional Digital Recording of Complex Historical Structures: The Case of Mevlana Museum. ISPRS International Journal of Geo-Information, 5(2)(18), 1-16. https://doi.org/10.3390/ijgi5020018

Błaszczak-Bąk, W. (2016). New optimum dataset method in LiDAR processing. Acta Geodynamica et Geomaterialia, 13(4), 381-388. https://doi.org/10.13168/AGG.2016.0020

Błaszczak-Bąk, W., Sobieraj-Żłobińska, A., \& Kowalik, M. (2017). The OptD-multi method in LiDAR processing. Measurement Science and Technology, 28(7), 75007509.

Corso, J., Roca, J., \& Buill, F. (2017). Geometric Analysis on Stone Façades with Terrestrial Laser Scanner Technology. https://doi.org/10.3390/geosciences7040103 Geosciences.

Del Pozo, S., Herrero-Pascual, J., Felipe-García, B., Hernández-López, D., Rodríguez-Gonzálvez, P., \& González-Aguilera, D. (2016). Multispectral radiometric analysis of façades to detect pathologies from active and passive remote sensing. Remote Sensing. https://doi.org/10.3390/rs8010080

Douglas, D. H., \& Peucker, T. K. (1973). Algorithms for the reduction of the number of points required to represent a digitized line or its caricature. Canadian Cartographer, 10(2), 112-122. https://doi.org/10.1002/9780470669488.ch2

Du, X., \& Zhuo, Y. (2009). A point cloud data reduction method based on curvature. Proceeding 2009 IEEE 10th International Conference on Computer-Aided Industrial Design and Conceptual Design: E-Business, Creative Design, Manufacturing - CAID and CD'2009, 914-918. https://doi.org/10.1109/CAIDCD.2009.5375038

Fregonese, L., Barbieri, G., Biolzi, L., Bocciarelli, M., Frigeri, A., \& Taffurelli, L. (2013). Surveying and monitoring for vulnerability assessment of an ancient building. Sensors (Switzerland). https://doi.org/10.3390/s130809747

Grilli, E., Menna, F., \& Remondino, F. (2017). A review of point clouds segmentation and classification algorithms. International Archives of the Photogrammetry, Remote Sensing and Spatial Information Sciences - ISPRS Archives, 339-344. https://doi.org/10.5194/isprs-archives-XLII-2-W3339-2017

Jo, Y., \& Hong, S. (2019). Three-Dimensional Digital Documentation of Cultural Heritage Site Based on the Convergence of Terrestrial Laser Scanning and Unmanned Aerial Vehicle Photogrammetry. ISPRS International Journal of Geo-Information, 8(2)(53),
1-14. https://doi.org/10.3390/ijgi8020053

Lin, Y.-J., Benziger, R. R., \& Habib, A. (2016). Planar-Based Adaptive Down-Sampling of Point Clouds. Photogrammetric Engineering \& Remote Sensing, 82(12), 955-966. https://doi.org/10.14358/PERS.82.12.955

Maglo, A., Lavoue, G., Dupont, F., \& Hudelot, C. (2015). 3D Mesh Compression: Survey, Comparisons, and Emerging Trends. ACM Computing Surveys, 47(3), 144. https://doi.org/10.1145/2693443

Nguyen, A., \& Le, B. (2013). 3D point cloud segmentation: A survey. IEEE Conference on Robotics, Automation and Mechatronics, RAM - Proceedings. https://doi.org/10.1109/RAM.2013.6758588

Oren, M., \& Nayar, S. K. (1994). Generalization of Lambert's reflectance model. Proceedings of the 21 st Annual Conference on Computer Graphics and Interactive Techniques - SIGGRAPH '94, 239-246. https://doi.org/10.1145/192161.192213

Pavlidis, G., Koutsoudis, A., Arnaoutoglou, F., Tsioukas, V., \& Chamzas, C. (2007). Methods for 3D digitization of Cultural Heritage. Journal of Cultural Heritage, 8(1), 93-98. https://doi.org/10.1016/j.culher.2006.10.007

Previtali, M., Barazzetti, L., Brumana, R., Cuca, B., Oreni, D., Roncoroni, F., \& Scaioni, M. (2014). Automatic façade modelling using point cloud data for energyefficient retrofitting. Applied Geomatics, 6(2), 95-113. https://doi.org/10.1007/s12518-014-0129-9

Suchocki, C, Jagoda, M., Obuchovski, R., Šlikas, D., \& Sužiedelytė-Visockienė, J. (2018). The properties of terrestrial laser system intensity in measurements of technical conditions of architectural structures. Metrology and Measurement Systems, 25(4). https://doi.org/10.24425/mms.2018.124886

Suchocki, C, \& Katzer, J. (2018). Terrestrial laser scanning harnessed for moisture detection in building materials - Problems and limitations. Automation in Construction https://doi.org/10.1016/j.autcon.2018.06.010

Suchocki, Czesław, \& Błaszczak-Bąk, W. (2019). DownSampling of Point Clouds for the Technical Diagnostics of Buildings and Structures. Geosciences. https://doi.org/10.3390/geosciences9020070

Suchocki, Czesław, Błaszczak-Bąk, W., Damięcka-Suchocka, M., Jagoda, M., \& Masiero, A. (2019). An example of using the OptD method to optimization of point clouds in the buildings diagnostics. 4th Joint International Symposium on Deformation Monitoring (JISDM), Athens, Greece.

Voegtle, T., Schwab, I., \& Landes, T. (2008). Influences of different materials on the measurements of a terrestrial laser scanner (TLS). International Archives of the Photogrammetry, Remote Sensing and Spatial Information Sciences, XXXVII(B5), 1061-1066.

Yastikli, N. (2007). Documentation of cultural heritage using digital photogrammetry and laser scanning. Journal of Cultural Heritage, 8(4), 423-427. https://doi.org/10.1016/j.culher.2007.06.003 